each project, with indications of the ecological background, the specific object of the study, and plans for publication of the results.

An interesting section of the report discusses experiments in research methods, particularly in relation to the possibilities of combining detailed, small-scale investigation with sampling methods, and the study of a wide range of variation within one culture. The organization of comparative studies and co-operation between different disciplines are two methods of study with which the Institute is particularly concerned.

Among the conferences organized by the Institute (some of which have already been noted in this journal) of particular interest is a joint conference held in February 1953 and attended by seven delegates from IRSAC and nine from the East African Institute. This conference coincided with a meeting of experts in the social sciences convened by the Council for Scientific Research in Africa South of the Sahara (C.S.A.), and observers attending that meeting took part in many of the sessions of the conference.

The Institute proposes to publish the work of its fellows in a series of papers called ' East African Studies ', to be published by the East African Literature Bureau. Monographs and comparative studies will be published in book form.

\title{
African Music
}

Aт a joint meeting of the Royal Africa Society, the Royal Empire Society, and the International African Institute, held in London on 6 October 1953, with Sir John Maud in the Chair, Mr. Hugh Tracey, founder and director of the African Music Society and author of Chopi Musicians, gave a lecture on African Music. Mr. Tracey spoke of the powerful integrative force of music and dance in African societies. All aspects of the life of the individual or the group-love, war, friendship, politics, domestic strife, as well as the community's moral judgements-are expressed in music and dance, and in these activities the African truly re-creates himself. For all those who wish to understand the African and to assist in his integration into the life of the modern world, nothing is more worthy of systematic and sympathetic study than African music and dance. The wide range of forms and of emotional content to be found in African music was strikingly illustrated by records, made from some of Mr. Tracey's own recordings. These included a melody of great charm and gaiety played on a flute by a Hima herd-boy, a vigorous choral number from Sukumaland, an intermezzo played by one of the famous Chopi xylophone orchestras, a legend from Buganda chanted by a local bard, and a concerted item from Southern Congo played by drums and xylophones, in which the peculiar snarl of weighted drums combined with the occasional high-pitched wail of voices to produce an intensely dramatic effect.

Mr. Tracey also showed a film of the remarkable dances performed by Tutsi dancers in Ruanda-Urundi; the dancers, most of them well over $6 \mathrm{ft}$. tall, displayed a sinuous grace of movement, enhanced by their mane-like head-dresses of banana fibre. 